
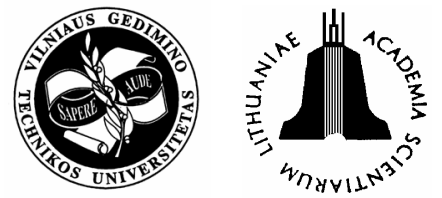

\title{
ESTIMATION OF EXPECTED CARGO OIL OUTFLOW FROM TANKER INVOLVED IN CASUALTY
}

\author{
Vytautas Smailys ${ }^{1}$, Mindaugas Česnauskis ${ }^{2}$ \\ ${ }^{1}$ Klaipeda University, Maritime Institute, I. Kanto g. 7, LT-92123 Klaipèda, Lithuania. \\ Phone +370 46398 739; Fax +370 46398 739. E-mail: vsmailys@ ji.ku.lt \\ ${ }^{2}$ Lithuanian Maritime Safety Administration, J. Janonio g. 24, LT-92251 Klaipeda, Lithuania. \\ Phone+370 46469 640; Fax+37046469600.E-mail: info@msa.lt
}

Received 16 April 2006, accepted 4 September 2006

\begin{abstract}
Modified version of simplified probabilistic methodology, designed for estimation of expected cargo oil outflow from tanker involved in casualty, is proposed. Suggested modified methodology can be used in the circumstances, when only very limited initial input data about the incident and tanker design is available. When applied in certain sea region (for example in Lithuanian sector of the Baltic Sea area), proposed methodology can be used in extremely short time spans, - estimation procedure requires several times less time than standard IMO methodologies, and gives quite insignificant errors of estimated oil outflow.
\end{abstract}

Keywords: crude oil tankers, accidents, expeditious evaluation of oil outflow.

\section{Introduction}

Transportation of crude oil and its products by sea, according to the data provided by the International Maritime Organization (IMO) comprises 1,8 billion tons per year and has no trend to decline. Certain quantities of oil, when transporting it by ships, partly legally, partly illegally or due to accidents, passes to the sea. Degree of harm and losses to the economy, caused by such pollution highly depends on peculiarities of certain accident, and in particular on measures taken to control the course of accident and expeditious application of appropriate combating means. Delay of half an hour or one hour to apply appropriate combating measures (in case of Klaipeda port, where stream of the Nemunas may transmit pollution), can stipulate expansion of pollution zone, increase damage to marine environment, and raise up combating costs.

The most important characteristics of estimation of expected oil outflow is expedition and precision of its execution, because the results of this exercise forms a base for expeditious selection of appropriate strategy and tactics, related with effective marine pollution combating.

Presently, different methods for estimation of expected oil outflow are used, which are quite universal, however they require considerably big amount of specific entry data and are more oriented to the evaluation of the degree of risk [1-3]. Due to this reason, accident liquidation process on this stage is usually based on professional judgment and no sound scientific methodologies are applied at all.

The objective of our research was to prepare modified methodology, suitable for expeditious application, and based on existing complex general purpose methods, designated for estimation of expected oil outflow. The research was done trying to ensure, that the said methodology has to be oriented to the specifics of Lithuanian ports, - technical characteristics of tankers, entering to them (draught, deadweight, design types), and hydrographical and navigational peculiarities of the area. Also we tried to ensure, that the new methodology has to be designed for easy, prompt and expeditious application, when user has very limited set of data about design of tanker and particulars of accident. For practical application of the methodology, the special PC based calculation algorithm was designed.

The proposed methodology in certain cases may supplement the theory of assessment of statistical probability of the technological transportation process [4] as well.

\section{Methodologies used for estimation of expected cargo oil outflow from tankers}

Prognosis of amount of oil, passed to the sea during the tanker accident, is mostly needed in two cases:

1) when prediction of possible extent of oil pollu- 
tion in particular port is exercised, having available input data on quantities of transported cargo oil, particulars of tankers used for such transportation and peculiarities of port and its oil terminals;

2) when preliminary expeditious estimation of occurred oil pollution is exercised, having only limited input technical data available (type of accident, port, type of tanker, quantity of cargo oil loaded, general particulars of tanker design).

Estimation of oil outflow from tanker is performed using combined methodologies [1, 2], according to which density of sea traffic in particular sea region, particulars of ships which can be potentially involved in the accident are used as an input data. The predicted output is the extent of the damage to the ship.

There are two IMO approved methodologies, designed to assess the extent of pollution prevention level of particular tanker - probabilistic [5], and simplified probabilistic methodology for evaluation of cargo oil outflow from tanker (simplified probabilistic methodology) [6, 7]. Both methodologies are based on best available tanker accident damage statistics [8]. This statistical data is expressed as probability density functions, which are used for estimation of oil outflow from tanker, that suffered side or bottom damage. These methodologies are also used by other researchers for assessment of risk level of particular tanker, and for selection of parameters, most suitable for "optimum risk tanker" [3].

It is estimated, that simplified probabilistic methodology $[6,7]$ is more convenient for use, as its application is not based on complex calculations.

When applying simplified probabilistic methodology, the volumes of each cargo tank and probabilities of possible damage of each of them is necessary to know, as an input data. Values of such probabilities can be calculated knowing main particulars of the hull, and parameters, qualifying the exact position and shape of each cargo tank, arranged in the tanker. However, this data in most cases is unavailable for expeditious use, as they are usually stored by ship owner and shipbuilder only, and cannot be retrieved promptly.

Aiming to ensure expeditious and, as precise as possible, estimations of cargo oil outflow having only limited primary information about the incident, there should be a possibility to use IMO approved methodologies, but only with very limited input data related to the accident.

Such application of IMO methodologies could be possible, if area or place of the incident had been known. In such case, quite big amount of data (construction types and sizes of tankers, characteristics of cargo oil, hydrographical conditions, relevant to the area of accident) is known in advance and can be entered in the algorithm of the accident development scenario.

The modification of IMO approved simplified probabilistic methodology, designated for expeditious estimation of oil outflow from tanker, which was involved in accident in Lithuanian oil terminal (Klaipèda, Būtingè) and its operational zones and suffered hull damage, is suggested in this work. The input data, necessary for application of proposed methodology, is limited to primary general data, related to the incident.

The proposed methodology can also be used as a complementing tool, when assessing navigational risk of tankers by methodologies, proposed by other researchers $[9,10]$.

\section{Composition of dataset related to tanker design}

In order to minimize amount of input data, necessary for oil outflow calculations, two assumptions are applied: the number of constructive designs of tankers is limited in certain sea region; their hull and cargo tank geometrical characteristics are similar.

Data containing main particulars of the ship, total amount of volumes of cargo tanks $V_{\Sigma}$, cargo tank arrangement scheme, may be accessed via Internet in databases such as "Equasis" or "LR Fairplay". However parameters defining length of cargo tanks as well as cargo tank positions along the waterline $\left(x_{f(i)}\right.$ and $\left.x_{a(i)}\right)$, see Fig 1 a, usually are not stored in these databases.

Analysis of tankers having different sizes and design types, done by the authors of this publication, revealed, that the length of all arranged cargo tanks for majority of tankers is the same, i.e. difference $x_{f(i)}-x_{a(i)}$ for the same tanker is constant value:

$$
\begin{aligned}
& x_{f(i)}-x_{a(i)}=\frac{L_{T}}{n_{\text {long }}}, \\
& L_{T}=L_{\perp}-\left(L_{f}+L_{a}\right),
\end{aligned}
$$

where $n_{\text {long }}$ - number of cargo tanks, arranged in one longitudinal line.

Analysis of different design types of tankers operating in the Baltic Sea and Lithuanian oil terminals (information contained in [8, 11-13] forms the basis of analysis) has revealed, that distances $L_{a}$ and $L_{f}$ mostly correlate with the length of the ship and deadweight.

Values of parameters $L_{a}, L_{f}$ and $L_{T}$ for different deadweight tankers, as estimated in performed research, are presented in Table 1. 

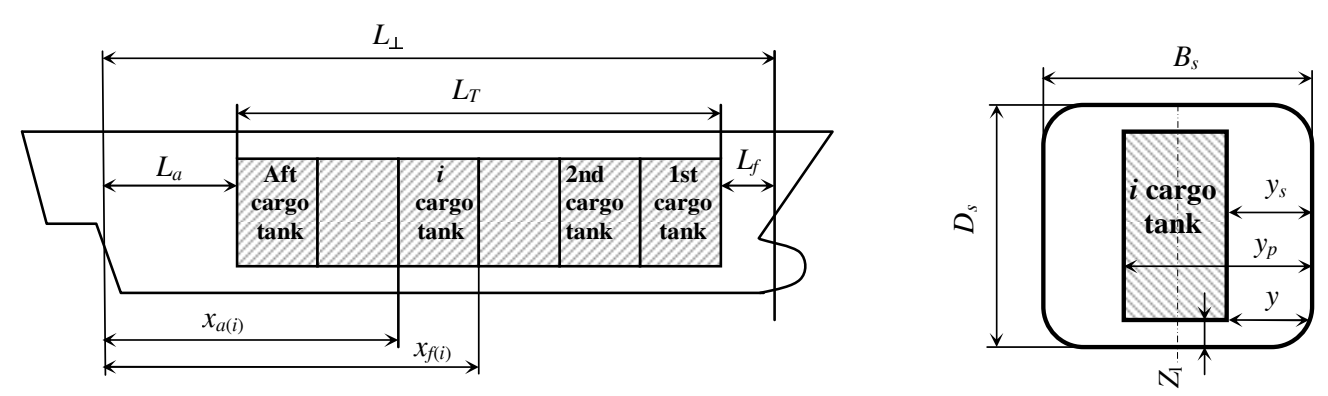

Fig 1. Dimensions of i cargo tank of the tanker:

a - profile-looking inboard, b- section looking forward; where: $x_{a}$-longitudinal distance from the aft to the aft most point on the cargo tank being considered; $x_{f}$-the longitudinal distance from the aft to the foremost point on the cargo tank being considered; $B_{S}$ - moulded breadth; $D_{s}$ - moulded depth; $L_{T}$ - cumulative length of cargo tanks, arranged in one longitudinal line along the waterline; $L_{f}$ - horizontal distance from front cargo compartment to front perpendicular; $L_{a}$-horizontal distance from aft cargo compartment to aft perpendicular; $Z_{1}$ - the vertical distance from the moulded baseline to the lowest point on the cargo tank being considered; $y$ - the minimum horizontal distance between the compartment under consideration and the starboard ; $y_{s}$ - the transverse distance from the starboard-most point on the cargo tank to vertical plate of the starboard; $y_{p}$ - the transverse distance from the port-most point on the cargo tank to vertical plate of the starboard

Table 1. Values of parameters $L_{a}, L_{f}$ and $L_{T}$ for tankers of different sizes, operating in the Baltic Sea

\begin{tabular}{|c|c|c|c|}
\hline DWT, $\mathrm{t}$ & $L_{a}$ & $L_{f}$ & $L_{T}$ \\
\hline $5000-35000$ & $\begin{array}{c}(0,23- \\
0,25) L_{\perp}\end{array}$ & $(0,07-0,05) L_{\perp} *$ & $(0,68-0,72) L_{\perp}$ \\
\hline $35000--50000$ & $\begin{array}{c}(0,21- \\
0,23) L_{\perp}\end{array}$ & $(0,06-0,05) L_{\perp} *$ & $(0,71-0,74) L_{\perp}$ \\
\hline $50000-80000$ & $\begin{array}{c}(0,20- \\
0,22) L_{\perp}\end{array}$ & $(0,06-0,05) L_{\perp} *$ & $(0,72-0,75) L_{\perp}$ \\
\hline $80000-150000$ & $\begin{array}{c}(0,19- \\
0,20) L_{\perp}\end{array}$ & $0,05 L_{\perp}$ & $(0,75-0,76) L_{\perp}$ \\
\hline
\end{tabular}

Performed analysis of design parameters of different tankers has shown, that damage probability of any of the cargo tank arranged in the tanker (except front cargo tanks), insignificantly depends on deviations, originating when comparing the actual shape of the tank with the shape of rectangular prism. This can be explained by the fact, that these insignificant shape deviations create very slight influence on distance deviations $Z_{1}$ and $y_{s}$ (see Fig $1 \mathrm{~b}$ ). The analysis also revealed, that difference $y_{p(i)}-y_{s}(i)$ (see Fig $1 \mathrm{~b}$ ) for tankers with cargo tanks arranged in one or two longitudinal lines, is equal for all arranged cargo tanks, (except front and aft cargo tanks). The deviations of aforementioned difference, as our research has shown, give insignificant errors for output result.
For tankers with cargo tanks arranged in three longitudinal lines, cargo tank arrangement scheme is presented in Fig 2 .

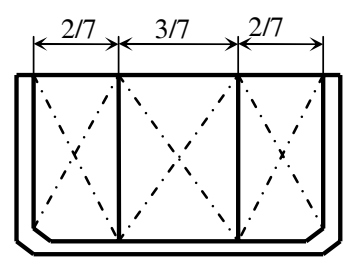

Fig 2. Typical cargo tank arrangement for tankers with cargo tanks arranged in three longitudinal lines [13]

In the absence of data, defining the level of bottom bulkhead of cargo compartments, assumption that these bottom bulkheads are horizontal is applied. Therefore, in order to calculate parameters $y, y_{s}$ and $y_{p}$, it is necessary to have available the cargo tank arrangement scheme, distance between inner and outer hulls (only for double hull tankers), $Z_{1}$ and $B_{S}$ (see Fig $1 \mathrm{a}$ ), as an input data.

Shapes of front cargo tanks, usually significantly differ from shapes of other tanks, arranged in the tanker, therefore we tried to analyse shapes of front cargo tanks, arranged in different size and design tankers, and to identify the dependence of parameter $y$ on $y_{s}$ (see Table 2, Fig $1 \mathrm{~b}$ ). For all remaining (except front) cargo tanks condition $y=y_{s}$ is applied. 
Table 2. Estimation of parameter $y$ by $y_{s}$ for front cargo tanks

\begin{tabular}{|l|l|l|l|}
\hline & $\begin{array}{l}\text { Tankers, } \\
\text { with tanks ar- } \\
\text { ranged in one } \\
\text { longitudinal } \\
\text { line }\end{array}$ & $\begin{array}{l}\text { Tankers, with } \\
\text { tanks arranged in } \\
\text { two longitudinal } \\
\text { lines } \\
\text { tanks }\end{array}$ & $\begin{array}{l}\text { Tankers, with } \\
\text { tanks arranged } \\
\text { in three longi- } \\
\text { tudinal lines }\end{array}$ \\
\hline $\begin{array}{l}\text { Port } \\
\text { side }\end{array}$ & - & $y=(0,75-0,85) y_{s}$ & $y=(0,60-0,70) y_{s}$ \\
\hline $\begin{array}{l}\text { Mid- } \\
\text { dle }\end{array}$ & $y=(0,70-0,80) y_{s}$ & - & $y=(0,40-0,60) y_{s}$ \\
\hline $\begin{array}{l}\text { Star- } \\
\text { board } \\
\text { side }\end{array}$ & - & $y=(0,75-0,85) y_{s}$ & $y=(0,75-0,85) y_{s}$ \\
\hline $\begin{array}{l}\text { Note: lesser values in the intervals should be used for } \\
\text { tankers, having most pronounced curvature in the front part of } \\
\text { the hull }\end{array}$ \\
\hline
\end{tabular}

It is worth to note, that quite wide intervals of parameter $y_{s}$ are indicated in Table 2 (up to $20 \%$ ). Calculations with marginal $y$ numbers for the same tanker have revealed, that such big differences of parameter $y$ have little influence on final result, - calculated oil outflow fluctuates up to $0,5 \%$.

Initial volume of $i$ cargo tank $V_{i i}, \mathrm{~m}^{3}$, can be calculated as product of its length, width, height and corresponding volumetric coefficient:

$$
V_{i i}=C_{i}\left(x_{f(i)}-x_{a(i)}\right)\left(y_{p(i)}-y_{s(i)}\right)\left(z_{u(i)}-z_{l(i)}\right),
$$

where $C_{i}$-volumetric coefficient of $i$ cargo tank.

Previously described analysis has shown, that cargo tank (except front and aft cargo tanks) shape deviations extremely slightly differ from the shape of rectangular prism (see Fig 3 ).

Therefore corresponding volumetric coefficients for these cargo tanks equal to 1.

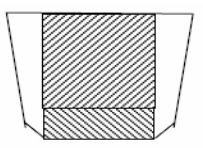

a

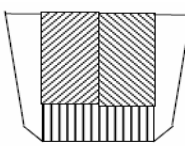

b

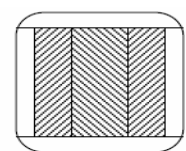

c

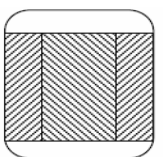

d
Fig 3. Tanker design types (section looking forward): a, $\mathrm{b}$ - double hull with horizontal longitudinal bulkhead across; c - double hull and double bottom; $\mathrm{d}$ - single hull and double bottom

In order to estimate volumetric coefficients for front and aft cargo tanks, the special research of 15 different design and deadweight tankers was executed. The results of this research has shown, that notwithstanding quite a wide range of tanker design types, the tankers with similar tonnage and cargo tank arrangement scheme can be grouped and corresponding intervals of volumetric coefficients for front and aft cargo tanks can be imposed to these groups (see Table 3). According to the data presented in the table, the volumetric coefficient for the same cargo tank may differ up to $10 \%$. Such variations do not trigger big errors, - calculated oil outflow fluctuates up to $1,5 \%$. Lesser values of volumetric coefficient indicated in the intervals (Table 3 ) should be used for tankers, having most pronounced curvature in the front part of the hull. In the absence of such data arithmetical average of marginal values which are indicated in the intervals should be used. For barges $C_{i}=1$ should be used for all cargo tanks.

After calculations of initial volumes $V_{i i}$, revised volumes $V_{i}$ of each $i$ cargo tank should be estimated:

$$
V_{i}=\frac{V_{\Sigma}}{\sum_{i=1}^{n} V_{i i}} V_{i i},
$$

where $V_{\Sigma}$ - total volume of all cargo tanks, known as one of main particulars of the tanker; $n$ - number of cargo tanks, arranged in the tanker.

By this it is assured, that $V_{\Sigma}$ equals to total volume of all revised volumes of cargo tanks:

$$
V_{\Sigma}=\sum_{i=1}^{n} V_{i}
$$

Calculations using this method were performed with 15 tankers. Errors of estimated volumes of each cargo tank comprised 2-7,5\%, comparing with the exact data, provided by tanker designers. Such errors trigger errors of calculated oil outflow up to $2,5 \%$.

Assumptions and simplifications proposed in this chapter provides with the possibility, on the basis of very limited set of accident related data, to form initial input dataset, necessary for application of simplified probabilistic methodology. This dataset can be revised at any stage of estimation, when additional information on tanker design and/or accident circumstances becomes available. Such revision of data assures better accuracy of final result.

Especially for application of proposed modified methodology, computer based calculation algorithm in Microsoft Excel environment was designed. The algorithm assures expeditious use of modified methodology and allows revision of initial input dataset at any stage of calculations. The application scheme of proposed modified methodology and peculiarities of application are presented in Fig 4.

\section{Validation of methodology}

In order to validate proposed modified methodology, comparative estimations were executed - estimation results obtained by using proposed modified methodology were compared with results obtained on the basis of strict application of IMO approved methodologies (Table 4). 
Table 3. Volumetric coefficients for tankers of different design types

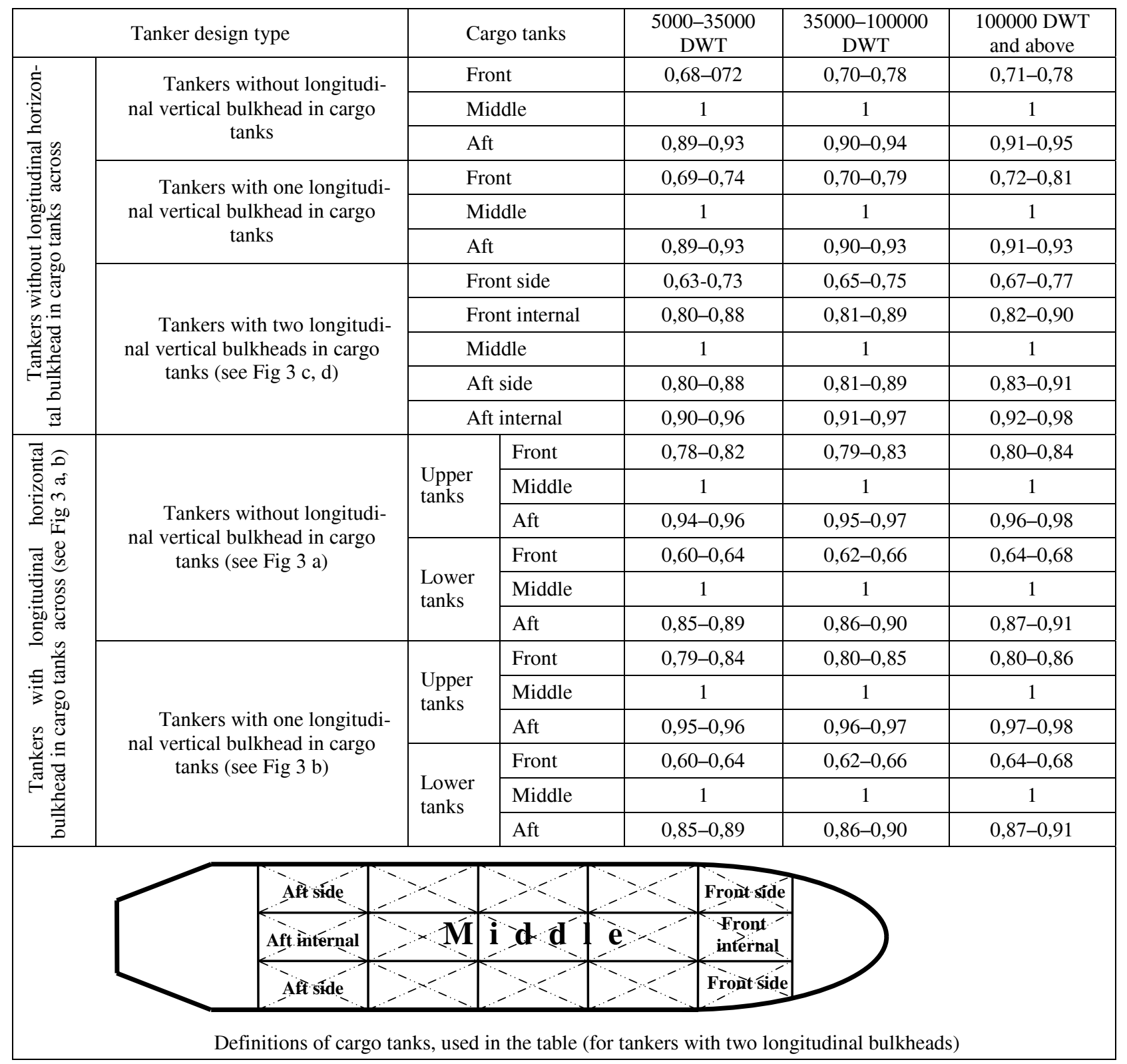

Also 19 different design tankers, comprising $33 \%$ of the number of all tankers which entered Klaipèda Port or Būtinge Oil Terminal in 2003, were estimated in terms of expected oil outflow in case of collision or grounding (Fig 5).

For illustration of practical use of methodology, the estimation of possible oil outflow from tanker "Princess Pia" ${ }^{1}$ was performed. The said tanker ran aground in the entrance channel of Klaipeda port in November of 2002, however no oil passed to the water in that time. Application of modified methodology provided with the result, that in case of oil

\footnotetext{
${ }^{1}$ Main particulars of the tanker: double bottom and single hull tanker with two longitudinal bulkheads across, cargo tank arrangement scheme $5 \times 3, L=216 \mathrm{~m} ; B=35,5 \mathrm{~m} ; d=11,028 \mathrm{~m} ; D=17,5 \mathrm{~m}, Z_{1}=$ $1,5 \mathrm{~m}, \mathrm{DWT}=55275 \mathrm{t}$.
}

outflow, the amount of oil spilled to the sea had amounted to $580 \mathrm{~m}^{3}$.

Performed estimations revealed (Table 4), that for double hull tankers parameter $O_{M}$ does not exceed 0,015 - the maximum permissible numeric value of mean outflow parameter, required by MARPOL Convention. For double $\operatorname{side}^{2}$ and single hull tankers parameter $O_{M}$ fluctuates from 0,026 to 0,094 .

\footnotetext{
2 Double side tankers are known as tankers with double hull arranged, and which were constructed before amendments to MARPOL convention on double hull design requirements entered into force. As a rule, the constructive design of double side tankers provides with better level of protection against pollution in case of collision or grounding than single hull, and worse level of protection than double hull.
} 


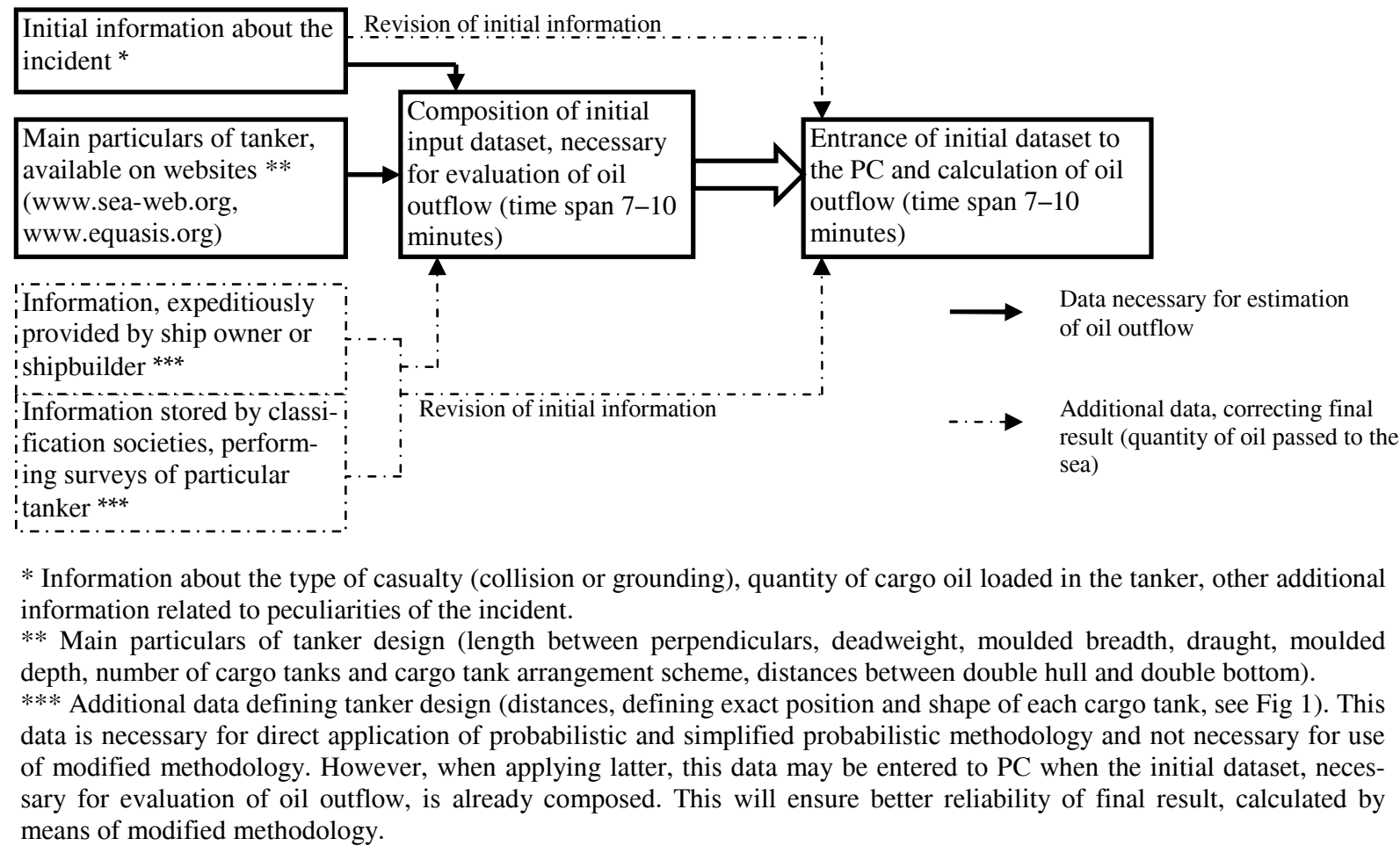

Fig 4. Application scheme of modified methodology and peculiarities

Table 4. Oil outflow parameters estimated by different methodologies for some tankers

\begin{tabular}{|c|c|c|c|c|c|c|c|c|c|c|c|c|}
\hline \multicolumn{9}{|c|}{$\begin{array}{l}\text { Set of initial input data for modified methodology (additional data, necessary for } \\
\text { calculations with other calculation methods, are not included) }\end{array}$} & \multicolumn{3}{|c|}{ Output results } & \multirow[t]{2}{*}{$\begin{array}{c}\text { Calculation } \\
\text { method }^{5}\end{array}$} \\
\hline DWT, $\mathrm{t}$ & $\begin{array}{l}\text { Cargo tank } \\
\text { arrangement } \\
\text { scheme }\end{array}$ & $\underset{\mathrm{m}}{D H^{1}}$, & $Z_{1}, \mathrm{~m}$ & $L, \mathrm{~m}$ & $B_{s}, \mathrm{~m}$ & $d_{s}, \mathrm{~m}$ & $D_{s}, \mathrm{~m}$ & $\begin{array}{c}0.98 V_{\Sigma} \\
\mathrm{m}^{3}\end{array}$ & $\begin{array}{c}O_{M S}{ }^{2} \\
\mathrm{~m}^{3}\end{array}$ & $\begin{array}{c}O_{M B}{ }^{3} \\
\mathrm{~m}^{3}\end{array}$ & $O_{M}{ }^{4}$ & \\
\hline \multirow{4}{*}{5000} & \multirow{4}{*}{$6 \times 2$} & \multirow{4}{*}{1} & \multirow{4}{*}{1,1} & \multirow{4}{*}{95} & \multirow{4}{*}{16,5} & \multirow{4}{*}{6,20} & \multirow{4}{*}{8,30} & \multirow{4}{*}{5848} & 102 & 64 & 0,0135 & 1 \\
\hline & & & & & & & & & $\mathrm{n} / \mathrm{d}$ & $\mathrm{n} / \mathrm{d}$ & 0,0120 & 2 \\
\hline & & & & & & & & & - & - & 0,0127 & 3 \\
\hline & & & & & & & & & 109,5 & 52,8 & 0,0126 & 4 \\
\hline \multirow{4}{*}{5000} & \multirow{4}{*}{$6 \times 2$} & \multirow{4}{*}{1,5} & \multirow{4}{*}{1,5} & \multirow{4}{*}{95} & \multirow{4}{*}{16,5} & \multirow{4}{*}{6,20} & \multirow{4}{*}{8,30} & \multirow{4}{*}{5848} & 65 & 49 & 0,0094 & 1 \\
\hline & & & & & & & & & $\mathrm{n} / \mathrm{d}$ & $\mathrm{n} / \mathrm{d}$ & 0,0090 & 2 \\
\hline & & & & & & & & & - & - & 0,0092 & 3 \\
\hline & & & & & & & & & 65,3 & 40,0 & $\mathbf{0 , 0 0 8 6}$ & 4 \\
\hline \multirow{4}{*}{40000} & \multirow{4}{*}{$5 \times 2$} & \multirow{4}{*}{2} & \multirow{4}{*}{2} & \multirow{4}{*}{170,2} & \multirow{4}{*}{30,96} & \multirow{4}{*}{11,72} & \multirow{4}{*}{17,03} & & 898 & 526 & 0,0144 & 1 \\
\hline & & & & & & & & 46784 & $\mathrm{n} / \mathrm{d}$ & $\mathrm{n} / \mathrm{d}$ & 0,0130 & 2 \\
\hline & & & & & & & & 40107 & - & - & 0,0137 & 3 \\
\hline & & & & & & & & & 936 & 449 & $\mathbf{0 , 0 1 3 7}$ & 4 \\
\hline & & & & & & & & & 1492 & 833 & 0,0156 & 1 \\
\hline 60000 & $6 \times 2$ & 2 & 2 & 2035 & 36 & 122 & 18 & 70175 & $\mathrm{n} / \mathrm{d}$ & $\mathrm{n} / \mathrm{d}$ & 0,0120 & 2 \\
\hline & & 2 & 2 & 20,5 & 50 & 12,2 & 10 & 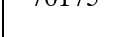 & - & - & 0,0138 & 3 \\
\hline & & & & & & & & & 1523 & 661 & 0,0143 & 4 \\
\hline & & & & & & & & & 2758 & 1275 & 0,0168 & 1 \\
\hline 95000 & $6 \times 2$ & 2 & 2 & 2352 & 418 & 1379 & 198 & 111111 & $\mathrm{n} / \mathrm{d}$ & $\mathrm{n} / \mathrm{d}$ & 0,0150 & 2 \\
\hline & & & & 200,2 & 71,0 & (1) & 1,0 & 111111 & - & - & 0,0159 & 3 \\
\hline & & & & & & & & & 2874 & 994 & $\mathbf{0 , 0 1 5 7}$ & 4 \\
\hline & & & & & & & & & 5018 & 1819 & 0,0177 & 1 \\
\hline 150000 & $6 \times 2$ & 2 & 2,32 & 264 & 48 & 16,8 & 24 & 175439 & $\mathrm{n} / \mathrm{d}$ & $\mathrm{n} / \mathrm{d}$ & 0,0160 & 2 \\
\hline & & & & & & & & & - & - & 0,0168 & 3 \\
\hline & & & & & & & & & 5338 & 1497 & $\mathbf{0 , 0 1 7 3}$ & 4 \\
\hline $\begin{array}{l}D H-\mathrm{dis} \\
{ }^{2} O_{M S}-\mathrm{m} \\
{ }^{3} O_{M B}-\mathrm{m} \\
{ }^{4} O_{M}=(0.4\end{array}$ & $\begin{array}{l}\text { nce between in } \\
\text { n oil outflow fr } \\
\text { in oil outflow fr } \\
\left.{ }_{M S}+0.6 O_{M B}\right)\end{array}$ & $\begin{array}{l}\text { er and ot } \\
\text { m side d } \\
\text { m bottor } \\
0.98 V_{\Sigma}\end{array}$ & $\begin{array}{l}\text { ter hulls, } \\
\text { amage, } m \\
\text { n damage } \\
\text { - mean oi }\end{array}$ & outflo & - & 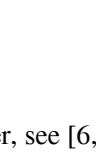 & & & & & & \\
\hline
\end{tabular}




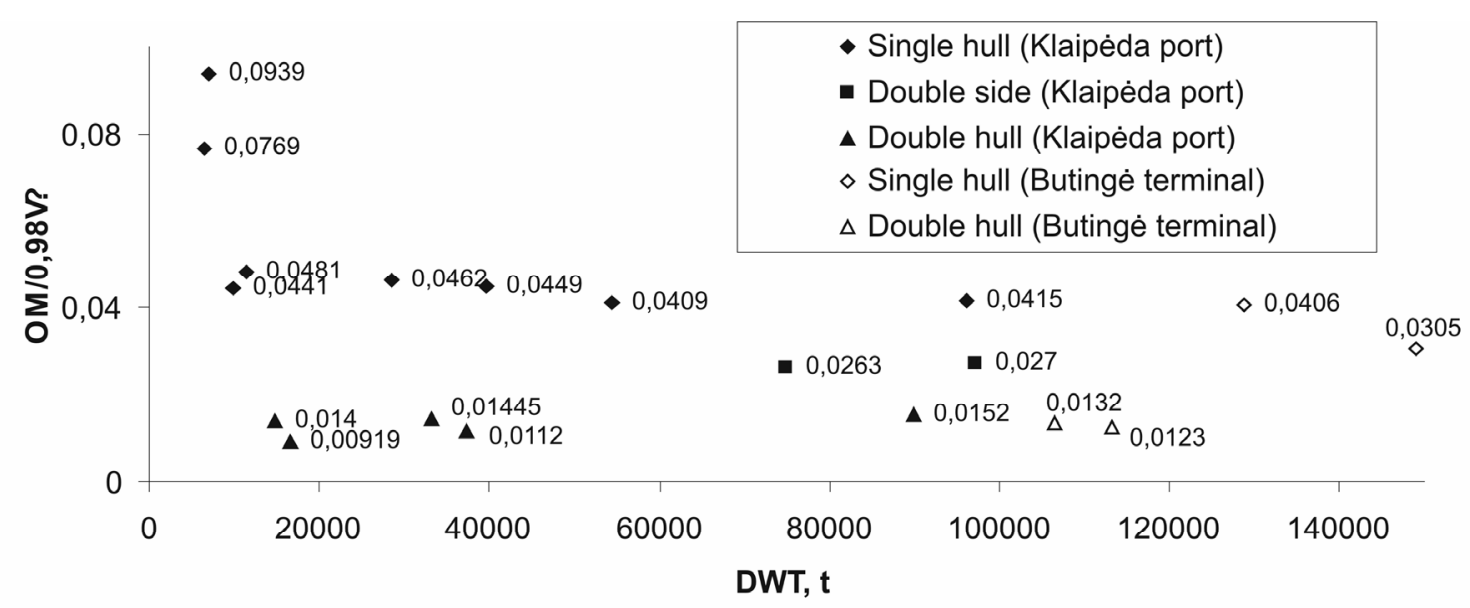

Fig 5. Estimated oil outflow parameters for some tankers, which entered Lithuanian ports in 2003

\section{Consideration of research results}

Numeric values of parameter $O_{M}$, estimated by modified methodology, were compared with values, obtained using IMO approved simplified probabilistic methodology [7] and using exact tanker design parameters. As shown in the Table 4, numeric values of $O_{M}$ differ from 3 to $18 \%$. It is worth to note, that when comparing output results estimated using probabilistic and simplified probabilistic methodologies (both approved by IMO) and using the same input data provided by the designer of the tanker, parameter $O_{M}$ differs up to $22 \%$ (this is consistent with IMO explanatory notes [7]).

Arithmetical averages of numeric values of parameter $O_{M}$, estimated by those two methods, were compared with numeric values of $O_{M}$, obtained using proposed modified methodology. As shown in the Table 4, numeric values of $O_{M}$ differ up to $7 \%$. Comparison of numeric values of parameters $\mathrm{O}_{\mathrm{MS}}$ and $O_{M B}$ reveals bigger errors. According to IMO explanatory notes [7] numeric values of output parameters $O_{M S}$ and $O_{M B}$ estimated by probabilistic methodology better corresponds reality. Therefore for more rigorous estimations of parameters $O_{M S}$ and $O_{M B}$ for tankers of greater size, numeric value of parameter $O_{M B}$ should be increased in 10-15\%, $O_{M S}$ reduced accordingly, $O_{M}$ keeping unchanged.

\section{Conclusions}

1. Application of IMO approved methodologies for estimations of oil outflow from tankers provides with reliable results, but only when quite big amount of input data is available. However, quite significant part of this data cannot be accessed swiftly. Therefore, the modification of IMO approved simplified probabilistic methodology, suitable for expeditious use in particular sea region, is proposed, in which, the amount of input data is reduced several times, knowing in advance the types of tankers, operating in this region, and their main design characteristics.

2. Comparative calculations revealed, that estimations of mean oil outflow, performed using modified methodology differ from those performed with exact methodologies by not more than $18 \%$, and this difference does not exceed differences of results, calculated by exact application of two different IMO methodologies.

3. Modified methodology is recommended for expeditious estimation of oil outflow from tankers, which were involved in casualties (collisions or groundings) in the oil terminals, situated in the Baltic ports and its premises. The methodology can also be successfully used for prognosis of possible oil outflows in the said region, or after adaptations, related to different construction designs of tankers, in other sea regions. 


\section{References}

1. Sonne Ravn, E.; Friis-Hansen, P. Predicting Collision Damage and Resulting Consequences. Department of Mechanical Engineering. DTU, Denmark, 2004.

2. Friis-Hansen, P.; Cerup Simonsen, B. GRACAT: Software for grounding and collision analysis. Journal of Marine Structures, Special issue on Ship Collision and Grounding, Vol 15, No 4-5 July-October 2002, p. 383402.

3. Brown, A. Optimum Risk Tanker. A Systematic Approach to a TAPS Tanker Design, Virginia Tech., 1999.

4. Baublys, A. Assessment of statistical probability of the technological transportation process. Transport, Vol XVII, No 4, 2002, p. 127-136.

5. Revised Interim Guidelines for the Approval of Alternative Methods of Design and Construction of Oil Tankers under Regulation 13f (5) of Annex I of MARPOL 73/78, resolution MEPC.110 (49), International Maritime Organisation, 2003.

6. Amendments to the Annex of the Protocol of 1978 relating to the International Convention for the Prevention of Pollution from Ships, 1973 (revised Annex I of MARPOL 73/78), resolution MEPC.117(52), International Maritime Organisation, 2004.

7. Explanatory notes on matters related to the accidental oil outflow performance under regulation 23 of the revised Annex I of MARPOL 73/78, resolution MEPC.117(52), International Maritime Organisation, 2004.

8. Statistical Analysis of Classification Society records for Oil tanker Collisions and Groundings, Lloyds Register STD Report No. 2078-3-2.

9. Paulauskas, V. Navigational risk assessment of ships. Transport, Vol XXI, No 1, 2006, p.12-18.

10. Paulauskas, V.; Plačienė, B.; Maksimavičius, R. Oil tanker navigational risk assessment (Tanklaivių navigacinès rizikos tyrimai). Sea \& Environment, Vol 2, Klaipeda, 2004, p. 29-32 (in Lithuanian).

11. Report of the IMO comparative study on Oil Tanker Design, resolution MEPC 32/7/15, International Maritime Organisation, 1992.

12. Double-hull tanker legislation: an assessment of the Oil Pollution Act of 1990, National Academy Press, Washington, D.C., 1998.

13. Comparative Study of Double-Hull and Single-Hull Tankers, Herbert Engineering Corporation, San Francisco, California, 1996. 